\title{
Contrast-induced Encephalopathy Following Embolization of Intracranial Aneurysms in Hemodialysis Patients
}

\author{
Noriaki MATSUBARA, ${ }^{1,2,3}$ Takashi IZUMI, ${ }^{1}$ Shigeru MIYACHI, ${ }^{1,3,4}$ Keisuke OTA, ${ }^{1}$ \\ and Toshihiko WAKABAYASHI ${ }^{1}$ \\ ${ }^{1}$ Department of Neurosurgery, Nagoya University Graduate \\ School of Medicine, Nagoya, Aichi, Japan; \\ ${ }^{2}$ Department of Neurosurgery, Chubu Rosai Hospital, Nagoya, Aichi, Japan; \\ ${ }^{3}$ Department of Neurosurgery \& Neuroendovascular Therapy, Osaka Medical \\ College, Takatsuki, Osaka, Japan; \\ ${ }^{4}$ Neuroendovascular Therapy Center, Aichi Medical University, \\ Nagakute, Aichi, Japan
}

\begin{abstract}
Contrast-induced encephalopathy is a very rare complication associated with endovascular treatment of intracranial aneurysms. Patients with renal dysfunction may be prone to developing contrast medium neurotoxicity as a result of delayed elimination of the contrast medium in renal metabolism. This article focuses on our experience with contrast-induced encephalopathy in patients with end-stage renal disease requiring hemodialysis. The authors retrospectively reviewed five patients diagnosed with contrast-induced encephalopathy who underwent aneurysm coil embolization at their institution from January 2006 to December 2015. During the 10-year period, embolization was performed in 755 cases, among which contrast-induced encephalopathy occurred in five patients $(0.66 \%)$. Three of the five patients were undergoing dialysis for chronic renal failure (one male and two female; mean age 66.7). Embolization for hemodialysis patients was performed in eight during the same period and the incidence of contrast-induced encephalopathy in hemodialysis patients is quite high in our series ( 3 of $8 ; 38 \%$ ). Procedures were performed in one for recurrence of unruptured anterior-communicating artery aneurysm and in two for unruptured basilar-tip aneurysm. Mean approximately $220 \mathrm{ml}$ of contrast media was used among three hemodialysis patients. All three patients showed an improvement or a control in symptoms soon after hemodialysis. Recovery of neurological symptoms was complete in two and almost normal in one within 1 week after intervention. Contrast-induced encephalopathy should be kept in mind as an expected complication of aneurysm embolization in hemodialysis patients. In hemodialysis patients with contrast-induced encephalopathy, performing hemodialysis is an effective treatment to improve symptoms early.
\end{abstract}

Key words: contrast-induced encephalopathy, embolization, intracranial aneurysm, hemodialysis, end-stage renal disease

\section{Introduction}

Contrast-induced encephalopathy is a very rare complication associated with endovascular treatment of intracranial aneurysms. The condition often arises in the occipital lobe with visual disturbance, but can also develop in other areas of the brain and, depending on the affected site, may cause various neurological abnormalities. ${ }^{1)}$ While symptoms are

Received June 8, 2017; Accepted August 3, 2017

Copyright $\odot 2017$ by The Japan Neurosurgical Society This work is licensed under a Creative Commons AttributionNonCommercial-NoDerivatives International License. often temporary and reversible, some reports have described cases in which permanent symptoms remained. ${ }^{1-3)}$ It is thought that the mechanism involves the contrast medium passing through the blood-brain barrier and leaking into the brain tissue, thereby causing neurotoxicity.,5) This report focuses on contrast-induced encephalopathy in hemodialysis patients.

\section{Materials and Methods}

In the present study, we retrospectively reviewed five patients diagnosed with contrast-induced encephalopathy who underwent intracranial aneurysm coil 
embolization including parent artery occlusion at our institution during the 10-year period from January 2006 to December 2015. We did not perform the intervention for the patients with markedly reduced kidney function to avoid precipitating end-stage renal disease induced by contrast medium but performed for those with chronic renal failure already maintained on regular hemodialysis. We usually tried to reduce the dose of contrast for the patients with moderate to severe renal insufficiency although we did not consider for hemodialysis patients. We used a nonionic iodinated contrast medium and routinely used iopamidol for intervention unless allergy or hypersensitivity for it in the patient. Imaging including control angiogram, rotational angiogram and angiogram in working projection) was performed with the contrast medium injected as an undiluted solution using an injector prior to insertion of the microcatheter and upon completion of embolization. During coil embolization, the contrast medium was diluted to approximately $2: 1$, and injection was manually performed. Patients diagnosed with contrast-induced encephalopathy were selected and examined from the clinical database in our department. Diagnosis of contrast-induced encephalopathy was made on the basis of postoperative neurological deteriorations and image findings in the computed tomography (CT)/ magnetic resonance imaging (MRI) study excluding thromboembolic or hemorrhagic complications. We regarded cortical contrast enhancement and edematous change in affected site as characteristic image findings. Informed written consent was obtained from all the patients and/or their guardian(s).

\section{Results}

During the 10-year period, coil embolization was performed in 755 cases (694 with unruptured aneurysm and 61 with ruptured aneurysm), among which contrast-induced encephalopathy occurred in five patients $(0.66 \%)$. The subject sample included two male and three female patients with a mean age of 64.2 years. All five patients underwent the intervention for unruptured intracranial aneurysm and incidence rate was $0.72 \%$ (5 of 694 patients with unruptured aneurysm). We carefully reviewed the clinical records, yet patients with ruptured intracranial aneurysm were not diagnosed as contrast-induced encephalopathy (it was not for sure but diagnosis might be difficult in ruptured aneurysms because of poor clinical condition and influence of subarachnoid hemorrhage in imaging). Contrast-induced encephalopathy was not observed after diagnostic angiogram for intracranial aneurysms during the same period. The aneurysm location was anterior circulation in two patients, and posterior circulation in three patients. All five patients had concurrent hypertension. The mean dose of contrast medium was approximately $250 \mathrm{ml}$. The contrast used was iopamidol in four patients, and iodixanol in one patient. Two of them without hemodialysis did not have severe renal dysfunction. Three of the five patients were undergoing dialysis for chronic renal failure (one male and two female; mean age 66.7).

Embolization for hemodialysis patients was performed in 8 ( 1 with ruptured and 7 with unruptured aneurysms) during the same period ( 8 of $755 ; 1.1 \%$ of embolization cases) and the incidence of contrast-induced encephalopathy in hemodialysis patients is $38 \%$ ( 3 of 8 ) in our series. Two of three had the history of polycystic kidney disease. Procedures were performed in one for recurrence of unruptured anterior communicating artery aneurysm and in two for unruptured basilar-tip aneurysm. Mean dose $220 \mathrm{ml}$ of contrast media was used. They showed an improvement or a control in symptoms soon after hemodialysis. Recovery of neurological symptoms was complete in two and almost normal in one within 1 week after intervention. Contrast-induced encephalopathy in the hemodialysis and the non-hemodialysis patients were summarized in Table 1.

\section{Representative Cases}

\section{Case 1}

The case subject was a 63-year-old woman with an unruptured anterior communicating artery aneurysm. The patient had the medical history of polycystic kidney disease and hypertension. Hemodialysis initiated five years previously for chronic renal failure caused by polycystic kidney disease. An unruptured anterior communicating artery aneurysm was detected during screening for dementia. The subject had undergone the first coil embolization eight years ago (three years prior to the start of hemodialysis), and the second coil embolization four years ago (one year after the start of dialysis). However, on both occasions the subject progressed with no perioperative complications. In addition, three-dimensional CT angiography performed using contrast medium one month before this intervention did not indicate neurological symptoms. Hemodialysis was performed on the day prior to embolization. A guiding catheter was inserted into the left internal carotid artery and the left and right anterior cerebral arteries were delineated by left internal carotid angiogram. The size of aneurysm was approximately $6 \mathrm{~mm}$ (Figs. 1A and 1B). 
Stent-assisted coil embolization was performed, and the procedure was completed without any intraoperative complications (Fig. 1C). Iodixanol 270 mgI/ml (Visipaque 270; Daiichi Sankyo, Tokyo, Japan) was used as the contrast medium at a dose of approximately $210 \mathrm{ml}$. Immediately after treatment, partial paralysis was observed in the left limbs, with moderate paralysis observed in the left leg. Post-treatment CT revealed a high-density area along the sulcus of the bilateral frontal lobes (Figs. 1D and 1E). Diffusion-weighted image (DWI) of MRI performed $3 \mathrm{hrs}$ after treatment revealed a faint hyper-intense area in the bilateral frontal lobe (Figs. 1F and $1 \mathrm{G}$ ). The patient was treated with dexamethasone because we routinely used steroids postoperatively (6.6 mg twice a day). However, the day following intervention the paralysis in the left limbs progressed and became severe. Moreover, the patient experienced a generalized convulsion. Head CT performed 20 hrs after treatment revealed a residual high density area along the bilateral (dominantly right) frontal lobes with edematous changes (Figs. 1H and 1I). On the day following intervention, hemodialysis was performed as initially planned. After hemodialysis, the left-sided paralysis improved. The paralysis then improved further after performing hemodialysis a second time postoperatively day 3 after intervention. On day 7 after intervention, only mild paralysis of the left arm persisted, and the subject was discharged from hospital. The patient had neurological improvement after discharge and recovered to normal at one month follow-up in outpatient clinic.

\section{Case 2}

The subject was a 74-year-old man with an unruptured basilar tip aneurysm. The patient had the medical history of diabetes, hypertension, liver cirrhosis and mitral insufficiency. Hemodialysis was initiated 10 years previously for chronic renal failure caused by diabetic nephropathy. The unruptured cerebral aneurysm was identified during brain health screening.

Hemodialysis was performed the day prior to embolization. A guiding catheter was placed into the left vertebral artery. The aneurysm was approximately $9 \mathrm{~mm}$ in size (Fig. 2A). Coiling of the aneurysm was performed using the double catheter technique and the procedure was completed without any intraoperative complications (Fig. 2B). Iopamidol $300 \mathrm{mgI} / \mathrm{ml}$ (Iopamiron; Bayer Yakuhin, Osaka, Japan) was used as the contrast medium at a dose of approximately $160 \mathrm{ml}$. Immediately after intervention the subject exhibited headache and vomiting, but there were no focal neurologic symptoms observed. The patient was treated with dexamethasone for postoperative routine use. However, several hours after intervention, the subject developed visual disturbance due to visual field defect, and mild disturbance of consciousness was observed. The day following intervention, the disturbance of consciousness progressed further. Head CT acquired the day after intervention revealed marked left side-dominant contrast medium residue in the bilateral occipital lobes and thalamus with edematous changes (Figs. 2C and 2D). At this point in time, contrast-induced encephalopathy was diagnosed, and hemodialysis was quickly performed. Immediately after dialysis, the disturbance of consciousness almost completely disappeared, but the visual disturbance remained. After performing dialysis on the second consecutive day after intervention, the visual disturbance almost entirely disappeared. MRI DWI acquired two-day after intervention revealed a hyper-intense area along the sulcus of the left occipital lobe, and faint hyper-intensity in the left thalamus (Figs. 2E and $2 \mathrm{~F}$ ). One week after intervention, the subject was discharged from hospital without sequelae.

\section{Discussion}

\section{Possible mechanism of contrast-induced encephalopathy}

Contrast-induced encephalopathy is a very rare complication associated with the endovascular procedure, especially in cerebral angiogram, as well as other vessel angiograms. Although the detailed mechanism of contrast-induced encephalopathy is not understood, it is thought that the repeated injection of the contrast medium into the same vessel causes the blood-brain barrier to disrupt, resulting in leakage of the contrast medium into the brain tissue, which causes neurotoxicity and various neurological abnormalities. ${ }^{4,5)}$

\section{Image findings of contrast-induced encephalopathy}

Typical image findings in head CT performed immediately after treatment include enhancement effect in the cortical areas of the brain with edema. Findings in MRI have not been frequently reported. These include abnormal T2, fluid attenuated inversion recovery (FLAIR) and/or DWI hyper-intensities in the affected cortices although sometimes these lesions may be subtle. ${ }^{6}$ In this study, 8 except 1 patients with contrast-induced encephalopathy demonstrated typical image findings of CT, that was, cortical enhancement with edema. And remaining one presented abnormal findings in MRI because CT was skipped for detailed examination. 
Table 1 Cases of contrast-induced encephalopathy in hemodialysis and non-hemodialysis patients The right half of Table 1 is on page 645 .

\begin{tabular}{|c|c|c|c|c|c|c|c|c|c|c|}
\hline $\begin{array}{l}\text { Case } \\
\text { no. }\end{array}$ & Age & Sex & $\begin{array}{c}\text { Cause of } \\
\text { renal } \\
\text { failure and } \\
\text { hemodialysis }\end{array}$ & $\begin{array}{l}\text { Duration of } \\
\text { hemodialysis } \\
\text { (year) }\end{array}$ & $\begin{array}{l}\text { Stage } \\
\text { of } \\
\text { CKD }\end{array}$ & Past history & $\begin{array}{l}\text { Previous } \\
\text { intervention } \\
\text { or angiogram }\end{array}$ & $\begin{array}{l}\text { Site of } \\
\text { aneurysm } \\
\text { (ruptured or } \\
\text { unruptured, } \\
\text { right or left) }\end{array}$ & $\begin{array}{l}\text { Size of } \\
\text { aneurysm } \\
(\mathrm{mm})\end{array}$ & $\begin{array}{l}\text { Endovascular } \\
\text { procedure }\end{array}$ \\
\hline \multicolumn{11}{|c|}{ Hemodialysis patients } \\
\hline 1 & 63 & $\mathrm{~F}$ & $\begin{array}{l}\text { Polycystic } \\
\text { kidney }\end{array}$ & 5 & 5 & Hypertension & $\begin{array}{l}\text { Coil } \\
\text { embolization } \\
\text { (twice) } \\
\text { (4-year and } \\
\text { 8-year } \\
\text { previously) }\end{array}$ & $\begin{array}{l}\text { Anterior } \\
\text { communicat- } \\
\text { ing artery } \\
\text { Unruptured }\end{array}$ & 6 & $\begin{array}{l}\text { Stent-assisted } \\
\text { coiling }\end{array}$ \\
\hline 2 & 74 & M & $\begin{array}{l}\text { Diabetes } \\
\text { mellitus }\end{array}$ & 10 & 5 & $\begin{array}{l}\text { Hypertension } \\
\text { Liver cirrhosis } \\
\text { Mitral } \\
\text { insufficiency }\end{array}$ & None & $\begin{array}{l}\text { Basilar-tip } \\
\text { Unruptured }\end{array}$ & 9 & $\begin{array}{l}\text { Coiling with } \\
\text { double } \\
\text { catheters }\end{array}$ \\
\hline 3 & 63 & $\mathrm{~F}$ & $\begin{array}{l}\text { Polycystic } \\
\text { kidney }\end{array}$ & 4 & 5 & $\begin{array}{l}\text { Hypertension } \\
\text { Angina } \\
\text { Gastric ulcer }\end{array}$ & None & $\begin{array}{l}\text { Basilar-tip } \\
\text { Unruptured }\end{array}$ & 12 & $\begin{array}{l}\text { Balloon-assisted } \\
\text { coiling }\end{array}$ \\
\hline \multicolumn{11}{|c|}{ Non-hemodyalysis patients } \\
\hline 4 & 70 & $\mathrm{~F}$ & NA & NA & $\begin{array}{c}2 \\
(\mathrm{eGFR} \\
67.0)\end{array}$ & Hypertension & None & $\begin{array}{l}\text { Posterior } \\
\text { cerebral } \\
\text { artery (P2) } \\
\text { Unruptured, } \\
\text { Left }\end{array}$ & 11 & $\begin{array}{l}\text { Stent-assisted } \\
\text { coiling }\end{array}$ \\
\hline 5 & 51 & $\mathrm{~F}$ & NA & NA & $\begin{array}{c}2 \\
(\mathrm{eGFR} \\
79.7)\end{array}$ & Hypertension & $\begin{array}{l}\text { Coil } \\
\text { embolization } \\
\text { 1-year } \\
\text { previously }\end{array}$ & $\begin{array}{l}\text { Internal } \\
\text { carotid } \\
\text { artery (C4) } \\
\text { Unruptured, } \\
\text { Left }\end{array}$ & 8 & $\begin{array}{l}\text { Stent-assisted } \\
\text { coiling }\end{array}$ \\
\hline
\end{tabular}

CKD: chronic kidney disease, eGFR: estimated glomerular filtration rate, NA: not applicable.

Contrast-induced encephalopathy and usage of contrast medium

While one cause is thought to be higher osmolality of the contrast medium than the blood, contrastinduced encephalopathy also arises with the use of iodixanol, a low osmolality contrast medium with osmolality approximately that of physiological saline. ${ }^{7,8)}$ Wilcox et al. reported that in an animal experiment, iodixanol and iopamidol exhibited the same ability to cross the blood-brain barrier. ${ }^{9)}$ In the present study, contrast-induced encephalopathy occurred with the use of iodixanol in patient 1 and iopamidol in others. The osmolality of iopamidol to physiological saline was approximately $3: 1$. In terms of contrast medium used, while some reports describe the case with low doses, ${ }^{10)}$ many suggest that event is associated with the injected dose of the contrast medium and the number of injections. ${ }^{11-13)}$ Uchiyama et al. reported that blood-brain barrier dysfunction is affected by the injection of high concentrations, low temperatures and repeated injections with short interval into the same blood vessel. ${ }^{13)}$ In this study, the mean dose of contrast medium was approximately $250 \mathrm{ml}$ (mean $220 \mathrm{ml}$ in hemodialysis and $285 \mathrm{ml}$ in non-hemodialysis patients). Excessive use of contrast medium was one of the factors in the development of encephalopathy in our series.

\section{Risk factor of contrast-induced encephalopathy}

Risk factors for contrast-induced encephalopathy include hypertension and renal dysfunction. ${ }^{1,8,14)}$ With regards to hypertension, it is thought that the blood-brain barrier is affected by a decline in blood vessels' autoregulation. All of the patients that we treated had a history of hypertension and hypertensive encephalopathy was possibly one of the differential diagnoses.

It is possible that patients with renal dysfunction may be prone to developing contrast medium neurotoxicity as a result of delayed elimination of the contrast medium in renal metabolism. It also appears that because hemodialysis patients do not eliminate the contrast medium outside the 
Table 1 Cases of contrast-induced encephalopathy in hemodialysis and non-hemodialysis patients The left half of Table 1 is on page 644 .

\begin{tabular}{|c|c|c|c|c|c|c|c|c|}
\hline $\begin{array}{l}\text { Iodixanol } \\
\text { (Visipaque270) }\end{array}$ & 210 & $\begin{array}{l}\text { Internal } \\
\text { carotid } \\
\text { arery } \\
\text { (Left) }\end{array}$ & $\begin{array}{l}\text { Hemiparesis } \\
\text { Convulsion }\end{array}$ & $\begin{array}{l}\text { Frontal lobe } \\
\text { (Bilateral) }\end{array}$ & Next day & Yes & 1 & 0 \\
\hline $\begin{array}{l}\text { Iopamidol } \\
\text { (Iopamilon300) }\end{array}$ & 160 & $\begin{array}{l}\text { Vertebral } \\
\text { artery } \\
\text { (Left) }\end{array}$ & $\begin{array}{l}\text { Blindness } \\
\text { Consciousness } \\
\text { disturbance }\end{array}$ & $\begin{array}{l}\text { Occipital lobe } \\
\text { (Bilateral) } \\
\text { Thalamus } \\
\text { (Left) }\end{array}$ & Next day & Yes & 0 & 0 \\
\hline $\begin{array}{l}\text { Iopamidol } \\
\text { (Iopamilon300) }\end{array}$ & 300 & $\begin{array}{l}\text { Vertebral } \\
\text { artery } \\
\text { (Left) }\end{array}$ & Blindness & $\begin{array}{l}\text { Occipital lobe } \\
\text { (Bilateral) }\end{array}$ & Same day & Yes & 0 & 0 \\
\hline $\begin{array}{l}\text { Iopamidol } \\
\text { (Iopamilon300) }\end{array}$ & 270 & $\begin{array}{l}\text { Internal } \\
\text { carotid } \\
\text { artery } \\
\text { (Left) }\end{array}$ & $\begin{array}{l}\text { Blindness } \\
\text { Hemiparesis } \\
\text { Agnosia }\end{array}$ & $\begin{array}{l}\text { Frontal (Left), } \\
\text { Parietal (Left), } \\
\text { and Occipital } \\
\text { lobe (Left) }\end{array}$ & NA & NA & 1 & 0 \\
\hline $\begin{array}{l}\text { Iopamidol } \\
\text { (Iopamilon300) }\end{array}$ & 300 & $\begin{array}{l}\text { Internal } \\
\text { carotid } \\
\text { artery } \\
\text { (Left) }\end{array}$ & $\begin{array}{l}\text { Hemiparesis } \\
\text { Aphasia } \\
\text { Consciousness } \\
\text { disturbance }\end{array}$ & $\begin{array}{l}\text { Frontal lobe } \\
\text { (Left) } \\
\text { Parietal lobe } \\
\text { (Left) }\end{array}$ & NA & NA & 0 & 0 \\
\hline
\end{tabular}

body through the urine, toxicity from the contrast medium may be delayed. There are a few reports of contrast-induced encephalopathy in patients with dialysis and severe renal impairment ${ }^{8,15-21)}$ although three out of five of the contrast-induced encephalopathy cases that we experienced were hemodialysis patients. In our limited number of series, the incidence of contrast-induced encephalopathy following embolization of intracranial aneurysm in hemodialysis patients is quite high. Embolization for the patients with severely reduced kidney function is usually avoided because of precipitating further deterioration of renal function induced by contrast medium although it would be performed for the patients already maintained on regular hemodialysis. Although severe renal failure is high risk for contrast-induced encephalopathy, it actually matters in hemodialysis patients.

\section{Treatment for contrast-induced encephalopathy}

Treatment for contrast-induced encephalopathy varies depending on the report, and remains controversial. As symptoms often improve in a few days with follow-up observation, conservative treatment is generally administered. Hydration and pharmacotherapy are commonly performed. ${ }^{1-3,6,10,11,21,22)}$ Steroids are the most-used drug for pharmacotherapy. While steroids are used for the purpose of improving cerebral edema, their therapeutic effects are expected to be achieved through stabilizing the blood-brain barrier. Because we routinely use steroid after coil embolization for several days and therefore, steroids were administered for all five patients with contrastinduced encephalopathy. Mannitol is another type of drug used to treat the condition. ${ }^{1,10,14,22)}$ Mannitol is a hyperosmotic diuretic and used for the purpose of improving cerebral edema although we did not use mannitol in this series. However, the effect is limited among the hemodialysis patients because of anuria/oliguria from renal impairment. Mannitol opens the blood-brain barrier but it could conversely induce contrast medium into the brain tissue due to delayed metabolism. The use of mannitol just during hemodialysis is worth considering but is not recommended in the daily use for contrast-induced encephalopathy. 


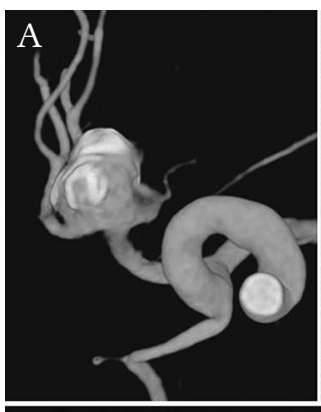

B

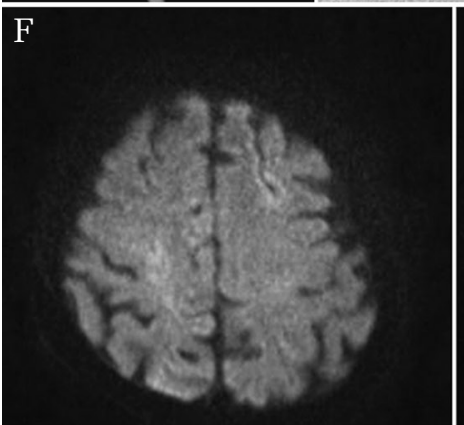

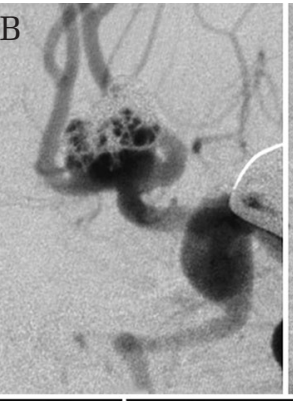

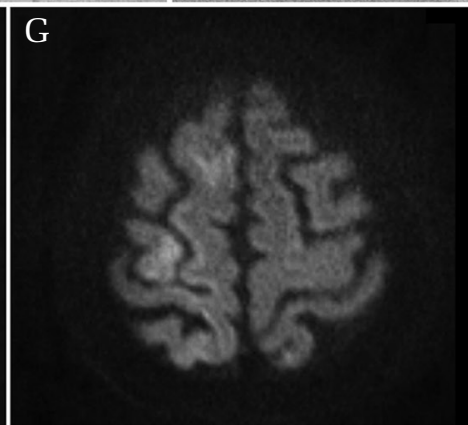

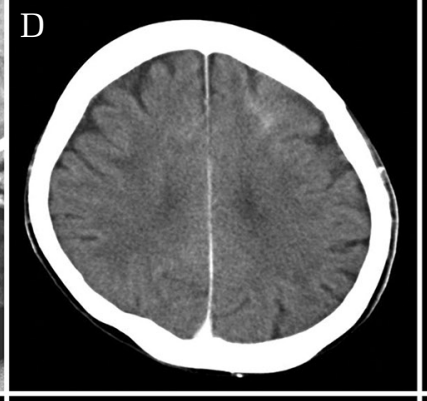
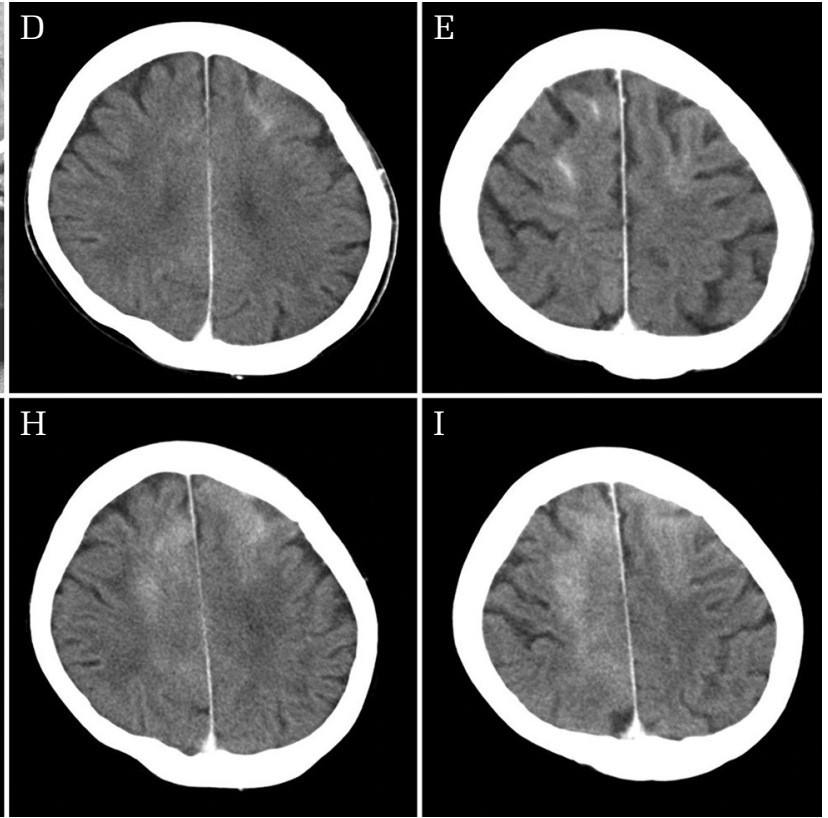

Fig. 1 Case 1. Left internal carotid angiogram demonstrating recurrence of anterior communicating artery aneurysm (A: three-dimensional reconstruction angiogram and B: conventional angiogram). C: Angiogram acquired after embolization by a stent-assisted technique showing complete occlusion of the aneurysm. $D$ and E: Non-contrast head CT acquired immediately after embolization revealed a cortical contrast enhancement along the sulcus of the bilateral frontal lobes. F and G: Diffusion-weighted image of MRI performed 3 hrs after treatment showing a faint hyper-intense area in the bilateral frontal lobes. $H$ and $I$ : Non contrast CT performed $20 \mathrm{hrs}$ after treatment demonstrating a residual cortical enhancement in the bilateral frontal lobes with edematous changes.

Hemodialysis and contrast-induced encephalopathy

The half-life of contrast medium in the blood of patients with normal renal function is approximately 2 hrs. In patients with severe renal dysfunction, however, it is approximately more than $16 \mathrm{hrs}^{23,24)} \mathrm{In}$ hemodialysis patients, it is more prolonged. In this series, cortical enhancement with edematous changes was still remained even one day after intervention (cases 1,2). It would be better to limit the dose of contrast medium during intervention in hemodialysis patients. Hemodialysis is useful for the removal of the contrast medium from the blood, with approximately $80 \%$ of the contrast medium having been removed within $4 \mathrm{hrs}{ }^{23,24)}$ In past case reports of contrast-induced encephalopathy, including patients undergoing hemodialysis and those with severe renal dysfunction, there have been cases where symptoms were improved by hemodialysis. ${ }^{8,19)}$ All of three of our patients showed an improvement or a control in symptoms after hemodialysis. Hemodialysis excretes the contrast medium and lowers the serum concentration. Therefore, the contrast medium leaked into the brain tissue is transferred to the blood, resulting in recovery from neurotoxicity. Dialysis disequilibrium syndrome is a rare but serious complication of hemodialysis ${ }^{25}$ and pathophysiology concerning this syndrome should be kept in mind. It presents neurological symptoms caused by cerebral edema attributed to an osmotic gradient between the brain and the blood as a result of rapid removal of urea by hemodialysis. Phenomenon like this syndrome could deteriorate cerebral edema due to contrastinduced encephalopathy by performing hemodialysis.

While the effectiveness of hemodialysis for the prevention and treatment of contrast-induced nephropathy has not been proved, ${ }^{23,26)}$ hemodialysis is an effective treatment method for contrast-induced encephalopathy in patients with severe renal dysfunction. Contrast-induced encephalopathy could present with severe neurological symptoms and permanent neurological symptoms could remain and hemodialysis should be considered as it can work to quickly remove the contrast medium in the blood.

\section{Conclusion}

We experienced three hemodialysis patients for contrast-induced encephalopathy, and found that the neurological symptoms improved after hemodialysis. Contrast-induced encephalopathy should be kept in mind as an expected complication of aneurysm embolization in hemodialysis patients. 

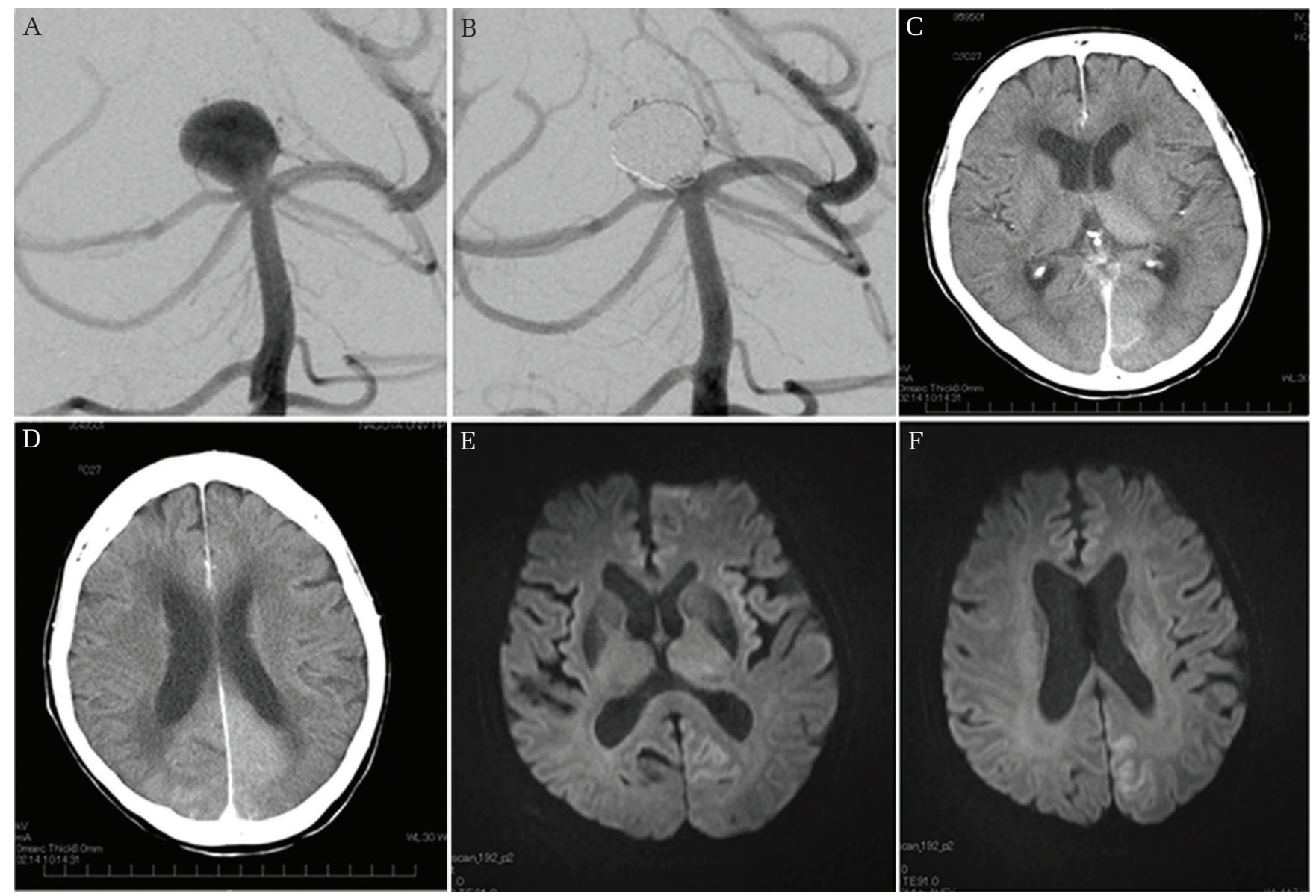

Fig. 2 Case 2. A: Left vertebral angiogram demonstrating an unruptured basilar tip aneurysm. B: Angiogram acquired after embolization by a double catheter technique showing complete occlusion of the aneurysm. C and D: Non-contrast head CT acquired the day after embolization showing a residual cortical enhancement in the bilateral occipital lobes and left thalamus with edematous changes. $E$ and F: Diffusion-weighted image of MRI performed 2 days after treatment showing a hyper-intensity along the sulcus of the left occipital lobe, and faint hyper-intensity in the left thalamus.

In hemodialysis patients with contrast-induced encephalopathy, performing hemodialysis is an effective treatment to improve symptoms early.

\section{Acknowledgement}

The author would like to thank Takumi Asai, MD and Kazunori Shintai, MD (Nagoya Medical Center), Takashi Yamanouchi, MD (Tosei General Hospital), Hayato Tajima, MD (Handa City Hospital), Tasuku Imai, MD, Masashi Ito, MD and Masahiro Nishihori, MD (Nagoya University Graduate School of Medicine), for their generous support in this study.

\section{Conflicts of Interest Disclosure}

The authors have no personal, financial interest in any of the materials or devices described in this article.

\section{References}

1) Leong S, Fanning NF: Persistent neurological deficit from iodinated contrast encephalopathy following intracranial aneurysm coiling. A case report and review of the literature. Interv Neuroradiol 18: 33-41, 2012

2) Niimi Y, Kupersmith MJ, Ahmad S, Song J, Berenstein A: Cortical blindness, transient and otherwise, associated with detachable coil embolization of intracranial aneurysms. AJNR Am J Neuroradiol 29: 603-607, 2008

3) Shinoda J, Ajimi Y, Yamada M, Onozuka S: Cortical blindness during coil embolization of an unruptured intracranial aneurysm-case report. Neurol Med Chir (Tokyo) 44: 416-419, 2004

4) Lalli AF: Contrast media reactions: data analysis and hypothesis. Radiology 134: 1-12, 1980

5) Uchiyama Y, Abe T, Hirohata M, et al.: Blood brainbarrier disruption of nonionic iodinated contrast 
medium following coil embolization of a ruptured intracerebral aneurysm. AJNR Am J Neuroradiol 25: 1783-1786, 2004

6) Saigal G, Bhatia R, Bhatia S, Wakhloo AK: MR findings of cortical blindness following cerebral angiography: is this entity related to posterior reversible leukoencephalopathy? AJNR Am J Neuroradiol 25: 252-256, 2004

7) Lee KK, Kang DH, Kim YS, Park J: Serious blood-brain barrier disruption after coil embolization of unruptured intracranial aneurysm: report of two cases and role of immediate postembolization CT scan. J Korean Neurosurg Soc 50: 45-47, 2011

8) Yan J, Ramanathan V: Severe encephalopathy following cerebral arteriogram in a patient with end-stage renal disease. Semin Dial 26: 203-207, 2013

9) Wilcox J, Wilson AJ, Evill CA, Sage MR: A comparison of blood-brain barrier disruption by intracarotid iohexol and iodixanol in the rabbit. AJNR Am J Neuroradiol 8: 769-772, 1987

10) Potsi S, Chourmouzi D, Moumtzouoglou A, Nikiforaki A, Gkouvas K, Drevelegas A: Transient contrast encephalopathy after carotid angiography mimicking diffuse subarachnoid haemorrhage. Neurol Sci 33: 445-448, 2012

11) Iwata T, Mori T, Tajiri H, Miyazaki Y, Nakazaki M: Repeated injection of contrast medium inducing dysfunction of the blood-brain barrier: case report. Neurol Med Chir (Tokyo) 53: 34-36, 2013

12) Kuhn MJ, Burk TJ, Powell FC: Unilateral cerebral cortical and basal ganglia enhancement following overdosage of nonionic contrast media. Comput Med Imaging Graph 19: 307-311, 1995

13) Uchiyama Y, Abe T, Tanaka N, et al.: Factors contributing to blood-brain barrier disruption following intracarotid injection of nonionic iodinated contrast medium for cerebral angiography: experimental study in rabbits. Radiat Med 24: 321-326, 2006

14) Guimaraens L, Vivas E, Fonnegra A, et al.: Transient encephalopathy from angiographic contrast: a rare complication in neurointerventional procedures. Cardiovasc Intervent Radiol 33: 383-388, 2010

15) Chen CW, Lin CJ, Guo WY, Liang IP: Mimicker of subarachnoid hemorrhage in a hemodialysis patient. Kidney Int 82: 940, 2012

16) García de Lara J, Vázquez-Rodríguez JM, SalgadoFernández J, Calviño-Santos R, Vázquez-González N,
Castro-Beiras A: [Transient cortical blindness following cardiac catheterization: an alarming but infrequent complication with a good prognosis]. Rev Esp Cardiol 61: 88-90, 2008

17) Gellen B, Remp T, Mayer T, Milz P, Franz WM: Cortical blindness: a rare but dramatic complication following coronary angiography. Cardiology 99: 57-59, 2003

18) Merchut MP, Richie B: Transient visuospatial disorder from angiographic contrast. Arch Neurol 59: 851-854, 2002

19) Muruve DA, Steinman TI: Contrast-induced encephalopathy and seizures in a patient with chronic renal insufficiency. Clin Nephrol 45: 406-409, 1996

20) Ozelsancak R, Erken E, Yildiz I, Giray S, Yildirim T, Micozkadioglu H: A very rare case of encephalopathy in a patient with end-stage renal disease: contrast agent, ioversol. Ren Fail 32: 1128-1130, 2010

21) Studdard WE, Davis DO, Young SW: Cortical blindness after cerebral angiography. Case report. J Neurosurg 54: 240-244, 1981

22) Lantos G: Cortical blindness due to osmotic disruption of the blood-brain barrier by angiographic contrast material: CT and MRI studies. Neurology 39: 567-571, 1989

23) Deray G: Dialysis and iodinated contrast media. Kidney Int Suppl 69: S25-S29, 2006

24) Lorusso V, Taroni P, Alvino S, Spinazzi A: Pharmacokinetics and safety of iomeprol in healthy volunteers and in patients with renal impairment or end-stage renal disease requiring hemodialysis. Invest Radiol 36: 309-316, 2001

25) Zepeda-Orozco D, Quigley R: Dialysis disequilibrium syndrome. Pediatr Nephrol 27: 2205-2211, 2012

26) Morcos SK, Thomsen HS, Webb JA; Contrast Media Safety Committee of the European Society of Urogenital Radiology (ESUR): Dialysis and contrast media. Eur Radiol 12: 3026-3030, 2002

Address reprint requests to: Noriaki Matsubara, MD, Department of Neurosurgery, Nagoya University Graduate School of Medicine, 65 Tsurumai-cho, Showa-ku, Nagoya, Aichi 466-8550, Japan. e-mail: mnoriaki0817@yahoo.co.jp 